\title{
Visiogauge: A Modified MBT Gauge
}

\author{
Garima Gaur ${ }^{1}$, Siddharth Mehta ${ }^{2}$, Kamal Bajaj $^{3}$, Priya R Sharma ${ }^{4}$, Esha Nagpal ${ }^{5}$, Kimi Mittal $^{6}$
}

\begin{abstract}
Bracket placement is an integral part of orthodontic treatment and it is needless to say that appropriate placement of the brackets is the most desirable. Over time, many devices and aids have been made to help an orthodontist to achieve this aim of placing the bracket to the most desirable position, but for some other reason, most of them have failed to achieve the desired position. In the present scenario, the most useable instrument for this purpose is the MBT gauge, which even though has its shortcomings, but has proven quite effective. One of its major disadvantages has been its non-ergonomic design because of which the orthodontist has no direct or indirect vision for the placement and as a result, the operator has to bend in a fatiguing posture or place it arbitrarily. To overcome this obstacle, we have custom-made "Visiogauge" which has an ergonomic-friendly design to help the doctor in achieving ease to use indirect vision. It not only would cater to the orthodontist to correct posture but would also enable him to achieve a higher level of precision in bracket positioning making it the required third eye. Keywords: Bracket positioning, MBT gauge, Visiogauge.

Journal of Mahatma Gandhi University of Medical Sciences \& Technology (2020): 10.5005/jp-journals-10057-0140
\end{abstract}

\section{INTRODUCTION}

Orthodontics is a branch of dentistry that deals with the alignment and leveling of the teeth while maintaining or improving the surrounding skeletal structures to obtain the desired results. ${ }^{1,2}$ To treat dental occlusion various appliances have been used. Most commonly, MBT bracket system is used in orthodontics which is the preadjusted kind of bracket system, i.e., torque and tip are incorporated in the bracket itself so to fully express its potential to move the tooth in the desired direction one has to place bracket at the FA point, i.e., mid-point of tooth structure which is formed by the intersection of the horizontal and vertical line. ${ }^{3-5}$ So to place bracket at that particular point orthodontist has to use a various instrument in the oral cavity such as MBT gauge and mouth mirror and probe, which sometimes create a fatiguing condition for the patient and the orthodontist also. This results in a decrease in the efficacy of the treatment and also increased time consumption. ${ }^{1}$

To overcome this problem and to create an ergonomic design present article discussed a new type of instrument "VISIOGAUGETHE THIRD EYE" which will not only give the ergonomic design to the orthodontist but also give better treatment result for the patient.

\section{Design}

The instrument is a modification of an MBT gauge with a rotating mirror $(3 \times 3 \mathrm{~cm})$ that is attached to the 19-gauge SS wire on one end and on the other end, it is attached to the rotating rubber ring which is snugly fit on the gauge (Fig. 1).

\section{Fabrication}

- The rubber material is placed over the gauge forming a rubber ring which surrounds the gauge from all surfaces (Fig. 2).

- On the other hand, 19-gauge SS wire is welded over the band material (Fig. 3).

- After welding the wire to the band, it is placed over the rubber ring on the gauge and after securing its position the band material is welded making it a snug fit with the rubber material (Fig. 4).
1,4,5 Department of Orthodontics and Dentofacial Orthopaedics, Mahatma Gandhi Dental College and Hospital, Jaipur, Rajasthan, India ${ }^{2}$ Department of Orthodontics, Manipal College of Dental Sciences, Manipal, Karnataka, India

${ }^{3,6}$ Department of Orthodontics, Maheshwari Dental Clinic, Jaipur, Rajasthan, India

Corresponding Author: Garima Gaur, Department of Orthodontics and Dentofacial Orthopaedics, Mahatma Gandhi Dental College and Hospital, Jaipur, Rajasthan, India, Phone: +91 8107091141, e-mail: ggaur66@gmail.com

How to cite this article: Gaur G, Mehta S, Bajaj K, et al. Visiogauge: A Modified MBT Gauge. J Mahatma Gandhi Univ Med Sci Tech 2020;5(2):66-68.

Source of support: Nil

Conflict of interest: None

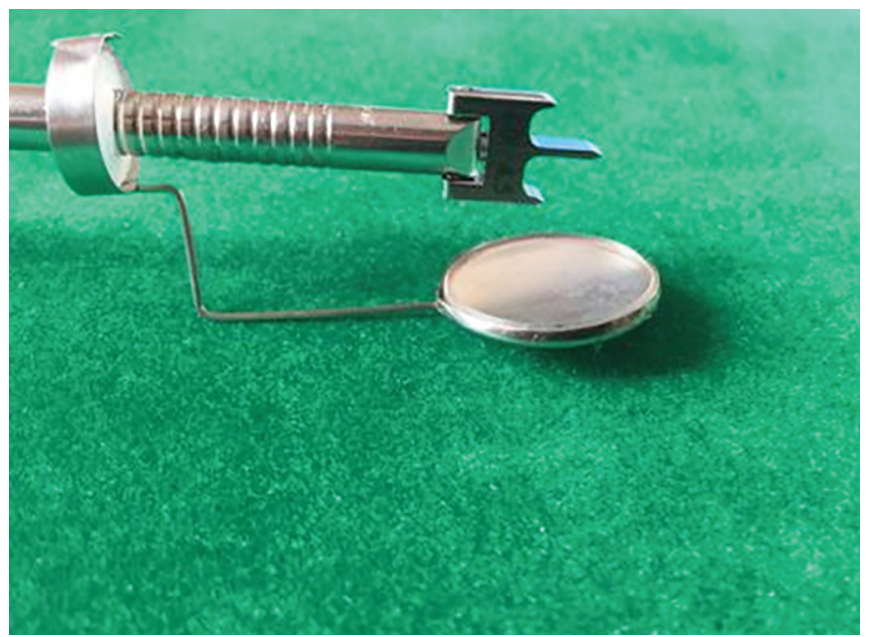

Fig. 1: Design of visiogauge

(0) The Author(s). 2020 Open Access This article is distributed under the terms of the Creative Commons Attribution 4.0 International License (https:// creativecommons.org/licenses/by-nc/4.0/), which permits unrestricted use, distribution, and non-commercial reproduction in any medium, provided you give appropriate credit to the original author(s) and the source, provide a link to the Creative Commons license, and indicate if changes were made. The Creative Commons Public Domain Dedication waiver (http://creativecommons.org/publicdomain/zero/1.0/) applies to the data made available in this article, unless otherwise stated. 


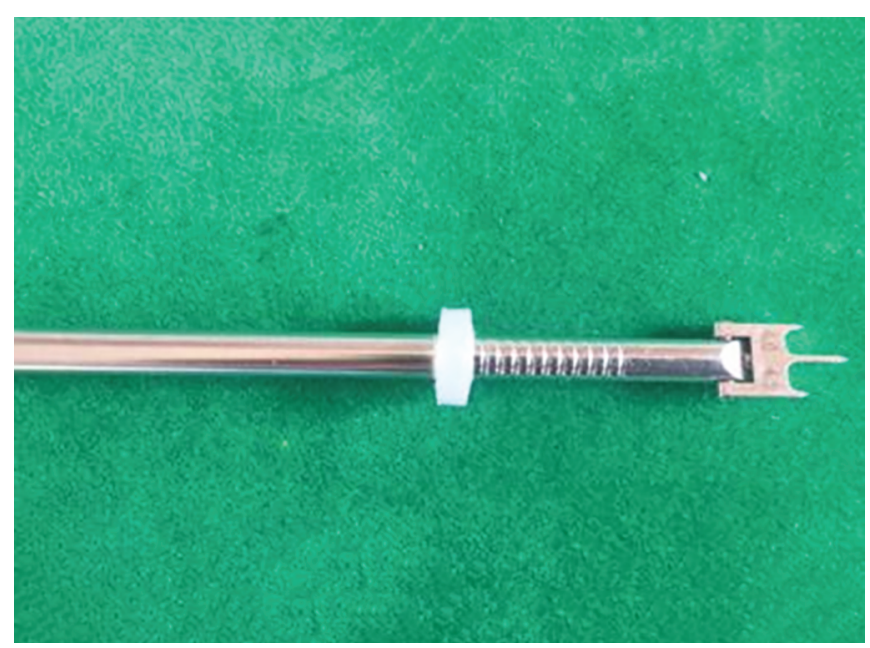

Fig. 2: The rubber material is placed over the gauge forming a rubber ring which surrounds the gauge from all surfaces

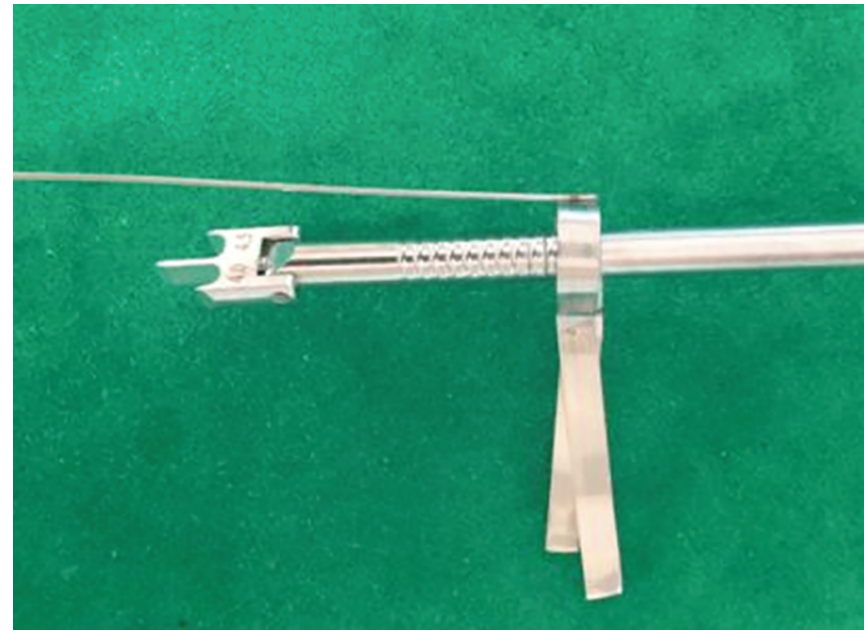

Fig. 4: After welding the wire to the band, it is placed over the rubber ring on the gauge and after securing its position the band material is welded making it a snug-fit with the rubber material

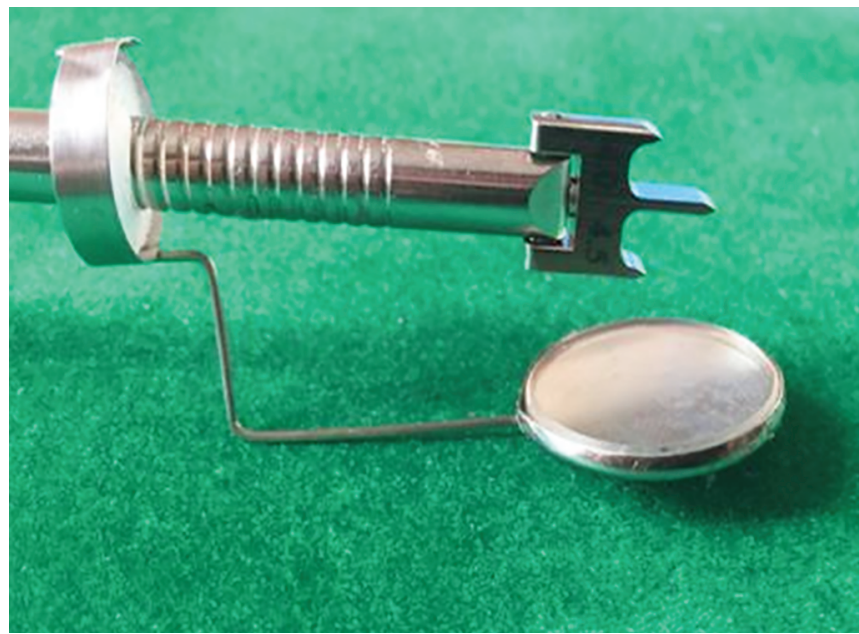

Fig. 6: Final design

- On the side where the ring is attached wire bending is done so that the mirror act parallel to the tooth surface and another end of the 19-gauge wire mirror is attached (Fig. 5).

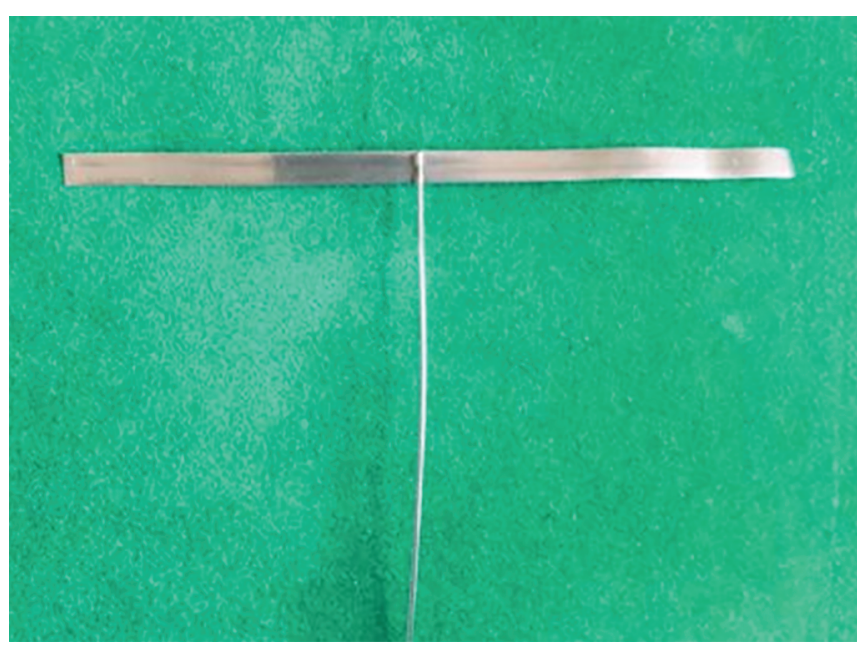

Fig. 3: On the other hand, 19-gauge SS wire is welded over the band material

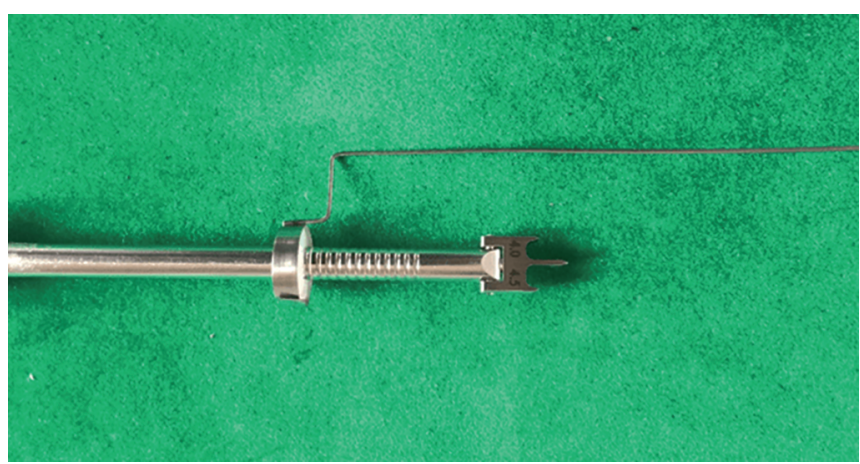

Fig. 5: On the side where the ring is attached wire bending is done so that the mirror acts parallel to the tooth surface and another end of the 19-gauge wire mirror is attached

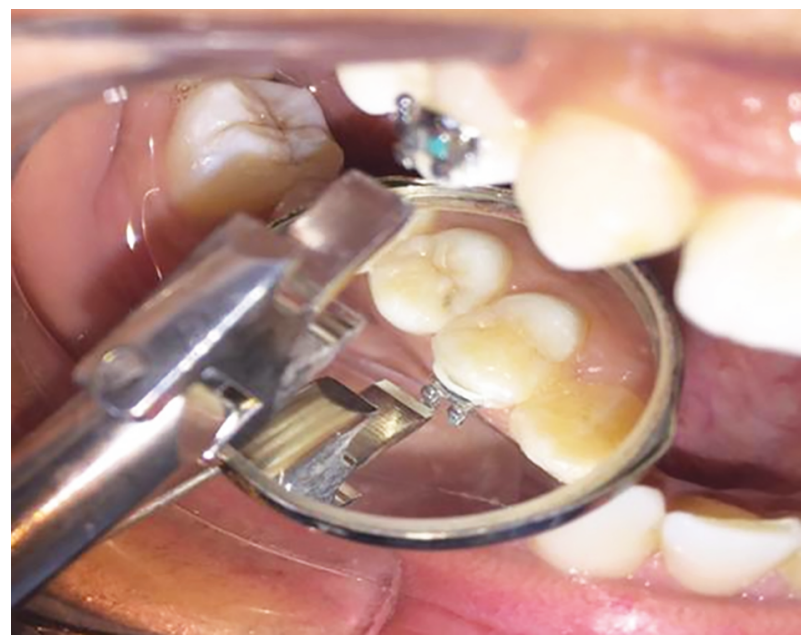

Fig. 7: Working with the visiogauge gives clinical accuracy

- Final design of the visiogauge.

Clinical Use and Advantages (Fig. 6)

- Working with the Visiogauge gives clinical accuracy (Fig. 7).

- It can be used in the anterior region as well as the posterior region (Fig. 8).

- This instrument creates an ergonomic condition for the orthodontist. 


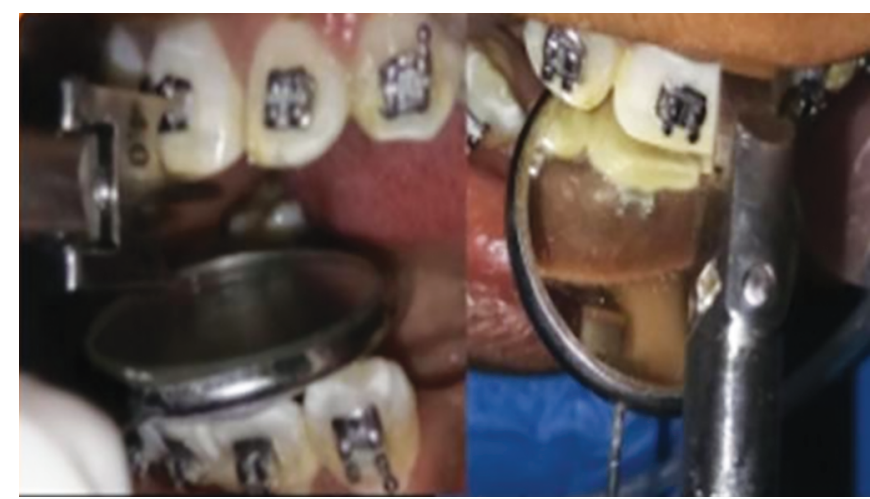

Fig. 8: It can be used in the anterior region as well as the posterior region

- Reduces chair-time.

- With the help of a rotating mirror can be used on both markings of the MBT gauge.

- Comfortable for the patient.

- No need for additional help/assistance.

\section{Discussion}

The practice of orthodontics involves laborious work that has to be carried out for a prolonged period to treat a patient's malocclusion. The majority of work of orthodontics has to be performed in a static position which causes the strain in the neck and lower back of the orthodontist. ${ }^{6}$ Bracket positioning is the heart of the orthodontics. ${ }^{1}$ One has to bond brackets on every tooth in a repetitive manner and for proper placement of the bracket on the tooth surface one has to use an MBT gauge and mouth mirror simultaneously which engage both hands of the orthodontist creating a tiresome condition for both orthodontist and patient. And in today's era of COVID where social distancing is the norm. An orthodontist has to limit staff in the operating area. Visiogauge which not only creates an ergonomic condition for orthodontist but also reduces the need of assistant which was previously required. With the help of a Visiogauge orthodontist can perform bonding procedure more precisely in very less time.

\section{Conclusion}

Visiogauge is a useful clinical instrument that verifies the bracket placement on anterior as well as posterior teeth and creates less stressful and easy to the handle condition for the orthodontist by creating the ergonomic condition.

\section{References}

1. Sharma NS, Shrivastava SS, Hazarey PV. A new 2D bracketpositioning gauge. J Indian Orthod Soc 2011;45(4):202-204. DOI: 10.1177/0974909820110409.

2. Ambekar A, Agrawal KD, Madansure A, et al. A-KAM, bracket positioning device. J Indian Orthod Soc 2018;52(2):147-148. DOI: 10.4103/jios.jios_219_16.

3. Armstrong $D$, Shen $G$, Petocz $P$, et al. A comparison of accuracy in bracket positioning between two techniques-localizing the centre of the clinical crown and measuring the distance from the incisal edge. Eur J Orthod 2007;29(5):430-436. DOI: 10.1093/ejo/cjm037.

4. Fowler. PV. Variations in the perception of ideal bracket location and its implications for the pre-adjusted edgewise appliance. Br J Orthod 1990;17(4):305-310. DOI: 10.1179/bjo.17.4.305.

5. McLaughlin RP, Bennett JC, Trevisi HG. Systemized orthodontic treatment mechanics. London: Mosby; 2001.

6. Hayes M, Cockwell D, Smith DR. A systematic review of mucoskeletal disorders among dental profession. Work 2010;35(4):419-499. DOI: 10.3233/WOR-2010-0979. 